\title{
Differences of Clinical and Laboratory Presentation in Positive and Negative Acid Fast Bacilli Pulmonary Tuberculosis Patients
}

\author{
Amila Hanifan Muslimah, ${ }^{1}$ Arto Yuwono Soeroto, ${ }^{2}$ Enny Rohmawaty ${ }^{3}$ \\ ${ }^{1}$ Faculty of Medicine Universitas Padjadjaran, ${ }^{2}$ Department of Internal Medicine Faculty of \\ Medicine Universitas Padjadjaran/Dr. Hasan Sadikin General Hospital Bandung, ${ }^{3}$ Department of \\ Pharmacology and Therapy Faculty of Medicine Universitas Padjadjaran
}

\begin{abstract}
Background: Based on bacteria status, tuberculosis is classified into positive and negative acid fast bacilli. This study was conducted to determine the differences of clinical and laboratory presentation in positive and negative acid fast bacilli pulmonary tuberculosis patients.

Methods: This study was an observational analytic study with a cross-sectional approach which used 338 medical records of patients with pulmonary tuberculosis at Direct Observational Treatment Short-course (DOTS) clinic Dr. Hasan Sadikin General Hospital from January to December 2012. Data collected were clinical and laboratory presentation for analytic study. Data about comorbid were collected for descriptive data.

Results: From 338 medical records, 223 were medical records of patients with pulmonary tuberculosis and 105 medical records of patients with comorbid. Twenty (18.01\%) comorbid were Human Immunodeficiency Virus (HIV). Acid fast bacilli negative was more $(121,51.9 \%)$ than acid fast bacilli positive $(112,48.1 \%)$. Differences of laboratory presentation were found in hemoglobin count $(\mathrm{p}=0.037)$, red blood cell count $(p=0.022)$, and erythrocyte sedimentation rate $(p=0.006)$ and not found in white blood cell count $(p=0.073)$, thrombocyte count $(p=0.766)$, serum glutamic oxaloacetic transaminase $(p=0.169)$, and serum glutamicpyruvic transaminase $(p=0.309)$. Difference of clinical manifestation was not found in fever $(p=1)$, cough $(\mathrm{p}=0.608)$, night sweats $(\mathrm{p}=0.09)$, dyspnea $(\mathrm{p}=0.210)$, and weight loss $(\mathrm{p}=0.269)$.

Conclusions: Differences between acid fast bacilli positive and negative are found in hemoglobin, red blood cell, and erythrocyte sedimentation rate laboratory examination. The highest comorbid of pulmonary tuberculosis patient is HIV. [AM].2016;3(2):286-91]
\end{abstract}

Keywords: Acid fast bacilli, clinical presentation, comorbid, laboratory presentation, tuberculosis

\section{Introduction}

The World Health Organization (WHO) reported in 2011 that there were more than 8.7 million new cases of tuberculosis, $75 \%$ which occurred in Asia, including Indonesia. Increasing case and problem have made tuberculosis global emergencies since 1993. Tuberculosis is diagnosed by finding acid fast bacilli in sputum specimen and classified into positive and negative acid fast bacilli. ${ }^{1}$ The amount of mycobacterium tuberculosis in pulmonary tuberculosis influences lesion condition. Wide lesion area gives worse signs and symptoms, including the clinical and laboratory presentation. ${ }^{2}$

In several region, sputum examination could not be performed due to lack of facility or patient has a difficulty in generating sputum. ${ }^{1,3}$ Data about clinical and laboratory presentation can be used as predictive value when sputum examination is not performed. These data can help physician to determine diagnosis and give appropriate treatment to reduce progression and transmission of diseases. Another factor that influences the sputum examination is comorbid diseases. These data also help in as predictive value. Recently, Dr. Hasan Sadikin General Hospital, a central referral hospital in West Java, does not have data about the clinical and laboratory diagnosis of negative acid fast bacilli. This study was conducted to determine the differences of clinical and laboratory diagnosis in positive and negative acid fast

Correspondence: Amila Hanifan Muslimah, Faculty of Medicine, Universitas Padjadjaran, Jalan Raya BandungSumedang Km.21, Jatinangor, Sumedang, Indonesia, Phone: +6285722974504 Email: amila.hanifan@gmail.com 
bacilli to pulmonary tuberculosis outpatient.

\section{Methods}

This study was an observational analytic study with a cross-sectional approach which used 223 medical records of patients with pulmonarytuberculosisatDirectObservational Treatment Short-course (DOTS) clinic Dr. Hasan Sadikin General Hospital from January to December 2012. This study was approved by Health Research Ethics Committee and all data included would be concealed.

Inclusion criteria were medical records of pulmonary tuberculosis patient. Among 498 medical records of pulmonary tuberculosis patient, 105 medical records had comorbid diseases. Data about comorbid were important as predictive value in acid fast bacilli examination, so it was collected as descriptive data. Avoiding bias in analysis study, medical records patient with comorbid and had incomplete data diagnosis acid fast bacilli were excluded in analysis. Two hundred and thirty three medical records of outpatient pulmonary tuberculosis patient without comorbid with complete acid fast bacilli data were selected. Because of less number medical record, these data were selected as total sampling. Clinical presentation variable in this study were fever, night sweating, weight loss, cough, and dyspnea. Laboratory presentation variable in this study were hemoglobin ( $\mathrm{Hb})$, white blood cell (WBC), red blood cell (RBC), thrombocyte, erythrocyte sedimentation rate (ESR), serum glutamic oxaloacetic transaminase (SGOT), and serum glutamic-pyruvic transaminase (SGPT).

Clinical and laboratory presentation in medical records were calculated by using prohibits analysis and then the results were classified based on each variable in negative and positive acid fast bacilli (AFB). Data about clinical presentation were made into table and statistical analysis using chi square test and kolmogorov smirnov test if chi square test was not required. Statistically significant was considered when $\mathrm{p} \leq 0.05$. The analysis was performed by comparing each group proportion and $\mathrm{p}$ value in the table presentation. Data about laboratory presentation were made into table and statistical analysis used unpaired T-test and Mann Whitney test if there were anomalies in the data distribution. Statistically significant was considered when $\mathrm{p} \leq 0.05$. Analysis was performed by comparing mean, standard deviation, confident interval (CI), and p-value in the table presentation.

\section{Results}

There are 233 medical records of pulmonary tuberculosis without comorbid and extra pulmonary tuberculosis. Acid fast bacilli negative was more than acid fast bacilli positive (Table 1).

Among 233 pulmonary tuberculosis patients, most of them were 14-33 years old. There were more male populations than female (Table 2).

One hundred and five medical records of pulmonary tuberculosis patient had comorbid diseases. Highest comorbid was Human Immunodeficiency Virus (HIV) (Table 3).

For number of proportion in positive acid fast bacilli (AFB), there were more cases in fever and fewer cases in dyspnea, while in negative AFB, there were more cases in fever and fewer cases in night sweat (Table 4).

Statistical analysis of fever used fisher test because chi square was not required. Night sweat, cough, dyspnea, and weight loss variable were used in chi square test. Statistically, there were no significant differences between positive and negative AFB ( $p>0.05)$ in all clinical presentations of patient.

Saphiro-wilk test analysis showed normal data distribution in hemoglobin count, RBC count, and ESR. Using unpaired t test analysis, these variable showed statistically significant differences $(p<0.05)$ between positive and negative acid fast bacilli. Statistically, there were no significant differences between positive and negative AFB ( $p>0.05)$ in $W B C$ and thrombocyte count. Using Mann-Whiteney as non parametric test analysis, SGOT and SGPT statistically did not show significant difference

Table 1 Acid Fast Bacilli Diagnosis of Pulmonary Tuberculosis Patient

\begin{tabular}{lcc}
\hline \multicolumn{1}{c}{ Acid Fast Bacilli Diagnosis } & N & \% \\
\hline Acid Fast Bacilli Negative & 121 & 51.9 \\
Acid Fast Bacilli Positive & 112 & 48.1 \\
Total & 233 & 100 \\
\hline
\end{tabular}


Table 2 Baseline characteristic Pulmonary Tuberculosis Patient

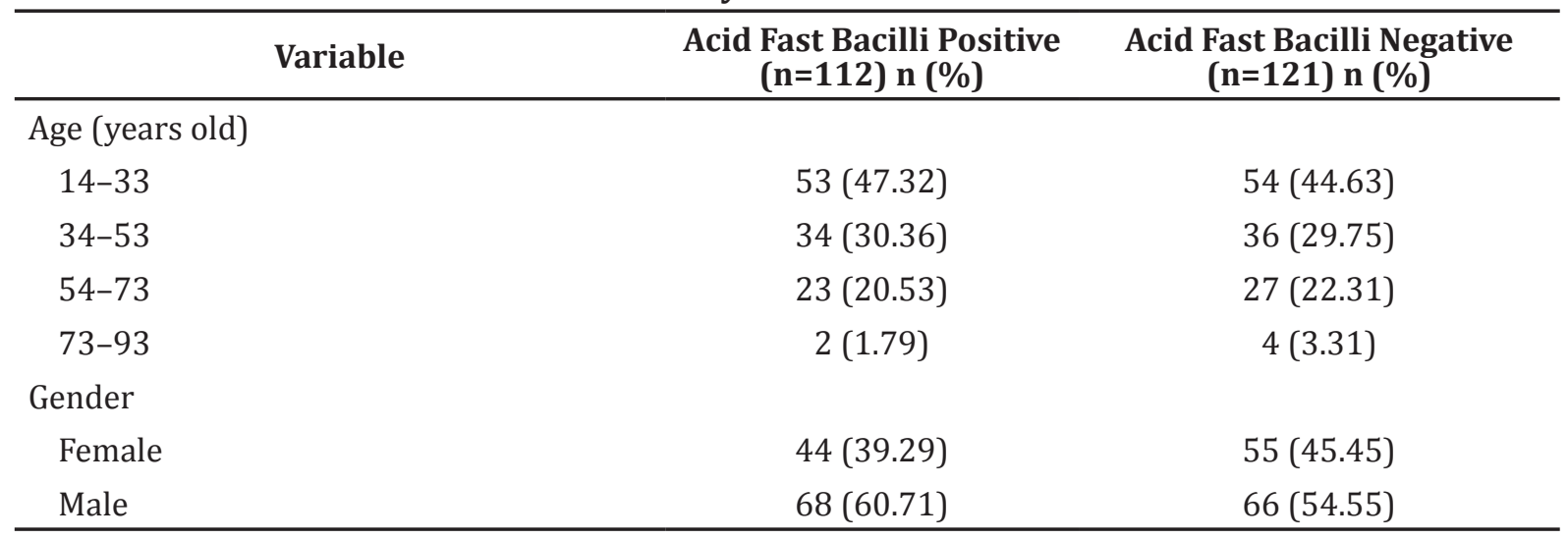

( $p=0.169$ and $p=0.309$ ) between positive and negative acid fast bacilli (Table 5).

\section{Discussion}

Tuberculosis as an infectious disease may predispose or trigger some chronic noncommunicable diseases. ${ }^{4}$ Several evidences describe the link between tuberculosis and several non-communicable diseases and their risk factors, such as diabetes mellitus, smoking, and pollution. ${ }^{5,6}$ In this study, 20 out of $85(18.01 \%)$ patient have human immunodeficiency virus (HIV). Another study by Mano et al. ${ }^{7}$ showed that $8.6 \%$ patients have HIV. Different proportion can occur because of different HIV/TB co-infection rate between Indonesia and India. Proportion of positive and negative acid fast bacilli in HIV in this study are $10(50.0 \%)$ and 9 (45.0\%). Several studies showed that HIV has higher rate acid fast bacilli negative than positive. These studies used positive HIV patient and perform algorithm to detect tuberculosis. So, it was discovered that most of them are smear negative patient. ${ }^{8,9}$

This study also showed that 19 (17.1\%) patients had diabetes mellitus. Another study by Alisjahbana et al. ${ }^{10}$ found that in Indonesia, $13.2 \%$ patients with TB have diabetes

Table 3 CoMorbid Diseases of Pulmonary Tuberculosis Patient

\begin{tabular}{lcccc}
\hline Co Morbid Diseases of Tuberculosis & $\begin{array}{c}\text { Positive AFB } \\
\text { (n) }\end{array}$ & $\begin{array}{c}\text { Negative AFB } \\
\text { (n) }\end{array}$ & $\begin{array}{c}\text { Not perform } \\
\text { sputum } \\
\text { examination } \\
\text { (n) }\end{array}$ & $\begin{array}{c}\text { Total } \\
\mathbf{n}(\%)\end{array}$ \\
\hline Community acquired pneumonia & 13 & 3 & 1 & $17(15.3)$ \\
Asthma bronchial & 1 & 3 & 0 & $4(3.6)$ \\
Diabetes Mellitus & 14 & 5 & 0 & $19(17.1)$ \\
Human Immunodeficiency Virus (HIV) & 10 & 9 & 1 & $20(18.01)$ \\
Hypertension & 2 & 6 & 0 & $8(7.2)$ \\
Pneumothorax & 4 & 1 & 2 & $5(4.5)$ \\
Chronic Obstructive Pulmonary Diseases & 2 & 0 & 1 & $4(3.6)$ \\
Carcinoma & 4 & 7 & 1 & $11(9.9)$ \\
Systemic Lupus Erythematosus & 1 & 1 & 0 & $3(2.7)$ \\
Rheumatic Heart Diseases & 2 & 1 & 0 & $3(2.7)$ \\
Others* & 8 & 9 & $17(15.3)$ \\
\hline
\end{tabular}

Note: *0thers case of comorbid diseases were two chronic bronchitis cases, one bronchiectasis case, one bronchopneumonia, two chronic kidney diseases case, one chronic renal failure case, one dengue hemorrhagic fever case, one urinary tract infection case, two evans syndrome cases, one gastropathy cases, one laryngitis case, two osteomyelitis cases, one vaginal septum case. 
Table 4 Clinical Presentation of Pulmonary Tuberculosis

\begin{tabular}{lcccc}
\hline \multicolumn{1}{c}{ Clinical Manifestation } & n & AFB Positive & AFB Negative & P \\
\hline Fever & 38 & $60 \%$ & $60.8 \%$ & 1 \\
Night sweat & 71 & $66.7 \%$ & $57.4 \%$ & 0.608 \\
Cough & 106 & $92.5 \%$ & $78.8 \%$ & 0.099 \\
Dyspnea & 42 & $43.7 \%$ & $65.3 \%$ & 0.210 \\
Weight loss & 79 & $85.1 \%$ & $73.1 \%$ & 0.269 \\
\hline
\end{tabular}

mellitus, thus there was a strong association between diabetes mellitus and tuberculosis patients. A systematic review reported that case control studies have odd ratio (OR) 1.167.83 in ranged of TB patients with DM. ${ }^{6}$

Early diagnosis and effective treatment of pulmonary tuberculosis cases that infect the community are the best ways in controlling tuberculosis. Study in Pakistan ${ }^{11}$ showed that the delay in diagnosis and inability to cure a high proportion of pulmonary smear positive cases are the main reasons of the increase of infection risk, high death rate, and multidrug resistance cases.

Diagnosis of tuberculosis is performed by sputum examination. ${ }^{1}$ This examination will detect acid fast bacilli with ziehl neelsen staining, ${ }^{3}$ and is classified into acid fast bacilli positive and acid fast bacilli negative. ${ }^{1}$ This study showed that among 235 pulmonary tuberculosis patients, 121 (51.4\%) had acid fast bacilli negative and $47.6 \%$ had acid fast bacilli positive. Study by Ishaq et al. ${ }^{11}$ showed that $104(52 \%)$ patients have acid fast bacilli positive and $96(48 \%)$ patients have acid fast bacilli negative. Different amount of data happened because of different sample size.

Mycobacterium tuberculosis amount in pulmonary tuberculosis influences lesion condition. Wide lesion area gives worse signs and symptoms, including the clinical and laboratory presentation. ${ }^{3}$ The commonest symptoms on patient presentations complained were cough, $92.5 \%$ patient AFB positive, and $78.8 \%$ AFB negative. Another common symptom was weight loss, presented in $85.1 \%$ AFB positive and $73.1 \%$ AFB negative patients. Night sweat was a symptom presented in $66.7 \%$ AFB positive patients and $57.4 \%$ AFB negative patients, fever in $60 \%$ AFB positive patients and $60.8 \%$ AFB negative patients, and dyspnea in $43.7 \%$ AFB positive patients and $65.3 \%$ AFB negative patients.

Another study by Ishaq et al. ${ }^{11}$, with $104 \mathrm{AFB}$

Table 5 Laboratory Presentation of Pulmonary Tuberculosis

\begin{tabular}{|c|c|c|c|c|c|c|}
\hline $\begin{array}{l}\text { Laboratory } \\
\text { Presentation }\end{array}$ & $\mathbf{n}$ & AFB Positive & $\mathbf{n}$ & AFB Negative & $\mathbf{p}$ & CI $95 \%$ \\
\hline $\begin{array}{l}\text { Hemoglobin gr/dl } \\
(\text { mean } \pm \text { s.d) }\end{array}$ & 14 & $11.65 \pm 1.98$ & 23 & $13.30 \pm 2.59$ & 0.037 & $0.10-3.19$ \\
\hline $\begin{array}{l}\text { WBC count/dl } \\
(\text { mean } \pm \text { s.d })\end{array}$ & 16 & $6488.50 \pm 2608.98$ & 16 & $8395.65 \pm 3453.40$ & 0.073 & $3453.40-863.35$ \\
\hline $\begin{array}{l}\text { RBC count trillion cell/l } \\
(\text { mean } \pm \text { s.d) }\end{array}$ & 9 & $4.19 \pm 0.71$ & 12 & $4.94 \pm 0.62$ & 0.022 & $0.12-1.38$ \\
\hline $\begin{array}{l}\text { Thrombocyte count/l } \\
\text { (mean } \pm \text { s.d) }\end{array}$ & 13 & $315230.77 \pm 119635.66$ & 22 & $302954.55 \pm 111126.90$ & 0.766 & $96458.20-71905.80$ \\
\hline $\begin{array}{l}\text { ESR mm/1st hr } \\
(\text { mean } \pm \text { s.d)) }\end{array}$ & 15 & $78.13 \pm 34.52$ & 31 & $52.58 \pm 23.74$ & 0.006 & $43.19-7.91$ \\
\hline SGOT, median (Q1-Q3) & 49 & $20.00(9-91)$ & 48 & $21.00(10-216)$ & 0.169 & $22.62-33.30$ \\
\hline SGPT, median (Q1-Q3) & 49 & $16.00(3-109)$ & 48 & $21.00(6-138)$ & 0.309 & $21.37-31.68$ \\
\hline SGOT, median (Q1-Q3) & 49 & $20.00(9-91)$ & 48 & $21.00(10-216)$ & 0.169 & $22.62-33.30$ \\
\hline SGPT, median (Q1-Q3) & 49 & $16.00(3-109)$ & 48 & $21.00(6-138)$ & 0.309 & $21.37-31.68$ \\
\hline
\end{tabular}


positive patients, showed that $84.61 \%$ have cough and 53.84\%xperience night sweating. This study was conducted through primary data collection and the increased frequency as compared to our study that can be as a result of complete data information.

A study by Alavi-Naini et al. ${ }^{12}$, with $350 \mathrm{AFB}$ negative patients, showed that $79.1 \%$ have fever, $45.4 \%$ have dyspnea, $26.2 \%$ experience weight loss, $14.8 \%$ experience night sweating. Different symptom frequency compared to our study can be as a result if data sample is larger. Other factors that influence clinical manifestation of tuberculosis patient are immunology factor, the quality of host defense, and mycobacteria. ${ }^{13,14}$

Statistical analysis of clinical presentation resulting fever $(p=1)$, cough $(p=0.608)$, night sweats $(p=0.09)$, dyspnea $(p=0.210)$, and weight loss $(p=0.269)$ do not differ between acid fast bacilli positive and negative. Another study by Alavi-Naini et al. ${ }^{12}$ showed association between night sweat and acid fast bacilli negative. This study used AFB negative patient with culture confirmation.

Siddiqi et al. ${ }^{15}$ reviewed systematically that patients with smear-negative tuberculosis experience night sweats for a longer time. Smear-positive patients have longer fever and experience weight loss than the smearnegative group. The studies have used four clinical criteria for diagnosis of smear-negative tuberculosis that have high sensitivity but low specificity.

The main limitation of this study was large number of incomplete data. Among 233 patients, complete data were found in $38(16.3 \%)$ patients having fever, $71(30.4 \%)$ patients experiencing night sweat, 106 (45.4\%) patients having cough, $42(18.0 \%)$ patients having dyspnea, and 79 (33.9\%) patients experiencing weight loss. Result from such an analysis should be used as a larger data sample.

This study also showed mean hemoglobin count, white blood cell, and red blood cell count that were higher in AFB negative than AFB positive. Mean thrombocyte count and erythrocyte sedimentation rate at the first hour was higher in AFB positive than AFB negative. Median for SGOT was 20.00 in AFB positive and 21.00 in AFB negative. Median for SGPT was 16.00 in AFB positive and 21.00 in AFB negative.

There were statistically significant difference of hemoglobin count, red blood cell count, and ESR first hour between AFB positive and negative $(\mathrm{p}=0.037, \mathrm{p}=0.022$, $\mathrm{p}=0.006)$. There was no statistically significant difference in white blood cell, thrombocyte count, SGOT, and SGPT between AFB positive and negative.

Laboratory examination of pulmonary tuberculosis can show mild anemia, white blood cell count within normal limit, SGOT and SGPT above normal level. ${ }^{3}$ Another study by Naini et al. ${ }^{12}$ showed there is association between acid fast bacilli negative and erythrocyte sedimentation rate $>45 \mathrm{~mm}$ and white blood cell count $<11000 / \mathrm{ml}$.

There were also large numbers of incomplete data. Among 233 patients, the patient with the complete data found was 37 $(15.8 \%)$ in hemoglobin count, $39(16.2 \%)$ in white blood cell count, $21(8.5 \%)$ in red blood cell, $35(15.0 \%)$ in thrombocyte count, 46 $(19.7 \%)$ in erythrocyte sedimentation rate, and 95 (40.7\%) in SGOT-SGPT. Statistically, the insignificant result could be caused by limited data sample.

In conclusion, there are statistically significant differences in laboratory presentation of hemoglobin count, red blood cell count, and erythrocyte sedimentation rate. There are no statistically significant differences in any clinical manifestation. Differences in the variable are needed to be assessed in adequately large study.

Data about clinical and laboratory presentation can be used as a predictive value for acid fast bacilli examination. These data can help physician to determine diagnosis and give appropriate treatment to reduce progression and transmission of diseases.

\section{References}

1. Departemen Kesehatan Republik Indonesia. Pedoman nasional penanggulangan tuberkulosis. Jakarta: Depkes RI; 2012.

2. Brooks G, Carrol K, Butel J, Morse S. Jawetz, Melnick \& Adelberg's Medical Microbiology. 24th ed. New York: The McGraw-Hill; 2007. p. 322.

3. Schlossberg D. Tuberculosis and nontuberculous mycobacterial infections. $6^{\text {th }}$ ed. Washington, DC: ASM Press; 2011.

4. Alisjahbana B, Sahiratmadja E, Nelwan EJ, Purwa AM, Ahmad Y, Ottenhoff TH et al. The effect of type 2 diabetes mellitus on the presentation and treatment response of pulmonary tuberculosis. Clin Infect Dis. 2007; 45(4):428-35.

5. Lin HH, Ezzati M, Murray M. Tobacco smoke, indoor air pollution and tuberculosis: a 
systematic review and meta-analysis. PLoS Medicine. 2007;4(1):e20.

6. Jeon CY, Murray MB. Diabetes mellitus increases the risk of active tuberculosis: a systematic review of 13 observational studies. PLoS Medicine. 2008;5(7):e152

7. Mano R, Muhammad GM. Study on HIV coinfection among pulmonary tuberculosis at a private medical college hospital. Asian Student Medical Journal. 2013;13(6):1-11.

8. Nguyen DTM, Nguyen HQ Beasley RP, Ford CE, Hwang LY, Graviss EA. Performance of clinical algorithms for smearnegative tuberculosis in HIV-infected persons in ho chi minh city, vietnam. Tuberculosis Research and Treatment. 2012;2012:360852.

9. Cain KP, McCarthy KD, Heilig CM, Monkongdee P, Tasaneeyapan T, Kanara $\mathrm{N}$, et al. An algorithm for tuberculosis screening and diagnosis in people with HIV. N Engl J Med. 2010;362(8):707-16.

10. Alisjahbana B, van Crevel R, Sahiratmadja E, den Heijer M, Maya A. Diabetes mellitus is strongly associated with tuberculosis in Indonesia. Int J Tuberc Lung Dis.
2006;10(6):696-700.

11. Ishaq KM, Ihsanullah, Amir M, Nisar $K$, Zaman M. Frequency of sputum positive acid fast bacilli cases among patients of pulmonary tuberculosis in tertiary care hospitals of northern pakistan. J Ayub Med Coll Abbottabad. 2010;22(2):56-60

12. Alavi-Naini R, Cuevas LE, Squire SB, Mohammadi M, Davoudikia AA. Clinical and laboratory diagnosis of the patients with sputum smear-negative pulmonary tuberculosis. Arch Iran Med. 2012;15(1):22-6.

13. Van Crevel R, Ottenhoff THM, van der Meer JWM. Innate immunity to mycobacterium tuberculosis. Clin Microbiol Rev. 2002;15(2):294-309.

14. Goyot-Revol V, Innes JA, Hackforth S, Hinks T, Lalvani A. Regulatory t cells are expanded in blood and disease sites in patients with tuberculosis. Am J Respir Crit Care Med. 2006;173(7):803-10.

15. Siddiqi K, Lambert M, Walley J. Clinical diagnosis of smear-negative pulmonary tuberculosis in low-income countries. Lancet Infect Dis. 2003;3(5):288-96. 